\title{
Preparing for Mental Health Review Tribunals: reports and dilemmas
}

\author{
B. Brockman, Consultant Forensic Psychiatrist, Reaside Clinic, Rubery, Rednal, \\ Birmingham B45 9BE
}

In the course of psychiatric training, doctors learn how to prepare a wide range of reports including those for Mental Health Review Tribunals. There are specific demands peculiar to this area of clinical work, particularly the challenge to clinicians to justify their diagnosis, current treatment, or future management of their patients in a public forum in front of the patient.

The Tribunal is a quasi court with legal powers but evidence is given while seated, and the Responsible Medical Officer's (RMO) written evidence is examined on average by four individuals, only one of whom is medically trained. For doctors not used to acting as expert witnesses in the courts, the Tribunal process can be an uncomfortable area of work.

This article is designed to aid the RMO or independent doctor in the preparation of written tribunal reports, highlight common problems posed when making recommendations, and assist in the preparation of oral evidence.

\section{Report compilation}

Under normal circumstances the patient has full access to the documents submitted by the managers detaining authority or trust to the Tribunal and it is important to discuss the report with the patient before its formal submission.

The report should contain a comprehensive summary of the history of the individual concerned. It should enable the reader to develop an overall understanding of the patient, outline the specific details of the illness and place the potential risk to self or others in context.

The format of the report should assist the Tribunal members who often have large quantities of information to read in advance. The reader should be helped with a logical sequence of information given in manageable bite-size pieces with headings for each relevant area.

It is important to avoid the use of medical jargon (or explain it simply where it is unavoidable). Longer sections of a report should be presented in chronological order with numbered points.
The report should comprise:

(a) Introduction

Name

Status

Admission date

Index offence

Information sources (e.g. school, social services, probation or medical records; reports including those of allied professionals, patient interview, and data gathered from informant sources such as relatives and liaison with other professional agencies in interview. Special regard should be paid to the 1991 Access to Medical Records Act, and issues of confidentiality, particularly the need to protect third party sources in certain circumstances.

Antecedents to current detention

(b) Personal history

(c) Family history

(d) Psychiatric history

(e) Medical history

(f) Past criminal history (where relevant)

(g) Course of current admission

Mental state on admission

Treatment used - physical psychological social

Response to treatment Current mental state Insight

Prognosis of illness Future risk assessment

(h) RMO's recommendation Aftercare plan where appropriate.

\section{RMO opinion}

RMOs can express their opinions on the options open to the Tribunal dependent on the category of detention ranging from absolute discharge, to deferred absolute discharge, conditional discharge, deferred conditional discharge, transfer, trial leave, and no discharge. The specific criteria that the RMO needs to consider for each Section of detention are 
expanded in the subsequent section on Tribunal authority. In essence the recommendation should be made having considered the powers of the Tribunal for each category of detention.

If the doctor recommends continued detention then he or she should clearly explain to the Tribunal the reasons citing the criteria (Section 72) he or she believes are fulfilled. Similarly, the doctor should make the case for why trial leave or deferred conditional discharge is being recommended. When recommending deferred conditional discharge, the doctor should expect to be asked and preferably make recommendations in the report about the approximate amount of time necessary to make the arrangements, in addition to why conditional discharge straight away cannot be recommended. In this case the doctor should provide a provisional aftercare plan for the Tribunal to consider. In circumstances when the doctor is recommending discharge for restricted patients, then this should contain a clear aftercare plan and any reservations if held.

\section{Aftercare plans}

Each care plan should address three main areas: the psychiatric care, social care, and the residence of patients (Table 1).

Under psychiatric care doctors should discuss the role of medication and any other treatment necessary for the patient. The care plan should clearly designate named members of the team, where this supervision should take place, and the frequency of consultations for each discipline. On occasions when it is felt necessary to have a condition of the patient attending a rehabilitation centre or other day facility, this should be described in detail.

Social aftercare can be provided either by the team social worker, district social worker, or probation officer when appropriate. Again the nature of supervision, frequency, and site of supervision should all be stipulated. The aftercare plan should contain details of the residence including details of type of supervision if the residence is in a hostel.

It is recommended good practice to appoint one member of the team as a key co-ordinator who has the responsibility to ensure that the patient understands the purpose of the supervision team, and co-ordinates the review case conferences after discharge.

\section{Tribunal authority}

The Tribunal has the authority to make decisions and recommendations, depending upon the status of detention. For clarity patients detained under Part II and Part III of the Act will be discussed separately.

For patients detained under Part II the Tribunal can direct discharge on the day (Section 72 [1] (2)), or
TABLE I

Aftercare plans

\begin{tabular}{|c|c|c|}
\hline & Profession & Site \\
\hline $\left.\begin{array}{l}\text { Psychiatric care } \\
\text { medication } \\
\text { supervision }\end{array}\right\}$ & $\begin{array}{l}\text { Doctor } \\
\text { CPN } \\
\text { Psychologist }\end{array}$ & $\begin{array}{l}\text { OPD } \\
\text { Home/clinic } \\
\text { OPD } \\
\text { Rehabilitation } \\
\text { centre? }\end{array}$ \\
\hline Social care & $\begin{array}{l}\text { Social worker/ } \\
\text { probation } \\
\text { officer }\end{array}$ & \\
\hline $\begin{array}{l}\text { Residence } \\
\text { Key coordinator }\end{array}$ & 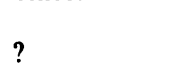 & $?$ \\
\hline
\end{tabular}

at a future date (S72 [3]). For patients detained under Part II of the Mental Health Act 1983 Section 2, the Tribunal must consider (i) whether or not the patient is suffering from mental disorder of a nature or degree which warrants his detention in hospital for assessment ... and (ii) if the detention is justified in the interests of his health or safety or protection of others. The Tribunal must discharge the patient if the patient fails to meet the criteria of either (i) or (ii) (S.72 [lb]).

For patients detained under Section 3, the Tribunal must consider (i) whether the patient is then suffering from mental illness, psychopathic disorder, severe mental impairment or mental impairment or from any of those forms of disorder, of a nature or degree which makes it appropriate for him to be liable to be detained in hospital for medical treatment and (ii) that it is necessary for the health or safety of the patient or from the protection of other persons that he should receive such treatment and (iii) whether the patient would be likely to act in a manner dangerous to other persons or to himself (S72 [1b]).

In cases not falling within paragraph (b) of subsection (1) S72 the Tribunal must consider (a) the likelihood of medical treatment alleviating or preventing a deterioration of the patient's condition and (b) in the case of patients suffering from mental illness or severe mental impairment, the likelihood of the patient if discharged being able to care for himself, to obtain the case he needs or to guard himself against serious exploitations.

For Part II patients failing to meet the criteria for continued detention the Tribunal can direct his discharge, on the day, or at a future date (S72 (3)). The Tribunal may make recommendations to the RMO and managers if it so wishes regarding leave of absence, transfer to another hospital or guardianship, or trial leave.

For patients detained under Part III of the Mental Health Act 1983, who are not subject to restriction 
orders, the Tribunal must consider the same criteria as in Part II (S72 [1]). The Tribunal has no formal powers to make recommendations under Part III but may still do so informally; therefore it is still appropriate for the RMO to offer advice about patients so detained.

For restricted patients the Tribunal must direct an absolute discharge if it judges the patient not to be suffering from mental disorder or from mental disorder of a nature or degree which warrants his detention in hospital ... or that his detention is not justified in the interests of his own health or safety or with a view of the protection of others (S72 [1]), and that it is not appropriate that he remain liable to recall to hospital for further treatment (S73 [1]).

The Tribunal must direct a conditional discharge if it considers the patient is not then suffering from mental disorder, or from mental disorder of a nature or degree which warrants his detention... or detention is not justified in the interests of his own health or safety or with a view to protection of others (S73 [2]) but should still be subject to recall (S42 [3]).

The Tribunal can also make a decision for a deferred conditional discharge if the patient fulfils the criteria, but the aftercare arrangements have not been finalised (S73 [7]).

The powers of the Tribunal may be summarised as follows:

(a) absolute discharge

(b) conditional discharge

(c) deferred conditional discharge

(d) transfer (not restricted patients)

(e) trial leave (not restricted patients)

(f) no discharge.

\section{Dilemmas}

Psychiatrists are used to making difficult decisions in degrees of uncertainty, but there are some specific dilemmas which arise during the process of making recommendations to the Tribunal. Four common issues for the psychiatrist and care team are:

(a) the incompletely treated patient

(b) the patient recently in remission

(c) patients suffering from psychopathic disorder

(d) restricted patients for whom the RMO recommends discharge when this is not recommended by the Home Secretary.

\section{Incomplete treatment}

Under these circumstances the RMO may be unable to make a recommendation for discharge. It is worth remembering that in the Mental Health Act treatment is defined to include "nursing ..., care, habilitation and rehabilitation, under medical supervision" and not just medication for identifiable symptoms of mental illness (S145 [1]).

Habilitation (Oxford Dictionary) is defined as "to furnish one with working capital" or "to qualify for office".

Rehabilitation (Oxford Dictionary) is defined as "to restore to effectiveness or normal life by training, especially after imprisonment or illness".

In cases where the RMO feels that the treatment is incomplete he or she will need to be able to explain to the Tribunal what else is required.

\section{Patients recently in remission}

For this group without overt symptoms of mental illness it is often a difficult case for the RMO to justify why a patient should not be discharged. Usually the greatest cause of concern for the RMO is the fact that the individual's recent improvement has not been fully tested out through degrees of individual responsibility and freedom. Under these circumstances it is not possible to judge whether the improvement is stable and will continue to be so in the community.

In trying to predict the probability of risk the RMO and care team examine the nature and course of the current episode of illness, the nature and course of past episodes, the patient's degree of insight, the patient's ability to co-operate with informal treatment if that was offered.

These factors should be considered in conjunction with the background of external social factors in the community such as the patient's proposed residence, family support network or difficulties, his indvidual personal vulnerability, and any associated substance abuse in the community which may put him at risk of relapse and risk to self or others.

At the Tribunal most patients declare their intent to take medication, but the RMO must consider the risk of relapse and risk to others in the event of non-compliance. These issues of durability of improvement, compliance and associated risk are difficult to predict and likely to be debated closely. The RMO should expect to be examined on the likely probability to assist the Tribunal with a difficult decision. This is often a difficult area for doctors to discuss with lawyers. There is a tendency to be asked closed questions, for example either/or questions, and in medicine these are rarely applicable. Mental illness and associated risk behaviour is rarely judged by questions of its existence or non-existence. In most cases it is a question of degree and probability; there are rarely any absolutes.

The Tribunal hears the evidence and must then apply the test ... does the patient still then suffer from mental disorder of a nature of degree ... or is the detention justified in the interests of his health or safety or the protection of others? 


\section{Recommending discharge for psychopathic patients}

In these cases the RMO is commonly faced with the dilemma of having admitted a patient suffering from personality disorder who now does not appear to be amenable to treatment because of his lack of ability or desire to co-operate with the therapy offered. Under the circumstances, when the patient no longer fulfils the criteria of the Mental Health Act that "treatment is likely to alleviate or prevent a deterioration of their condition" then the doctor may be asked to give an answer to the question "is not being in hospital care?". The RMO should be prepared to explain what intervention has been used, the reasons why treatment is not tenable and hence the reason why discharge is appropriate.

Recommending discharge when not in agreement with the Home Secretary

Finally, another dilemma faced by the RMO is when his or her opinion is that the Tribunal recommend the discharge of a restricted patient and the Home Secretary is not in agreement. In these cases the RMO should clearly discuss the risk of relapse of mental illness and subsequent offending with concern to public safety issues. It is helpful to review the antecedent factors at the time of the index offence and to evaluate what has changed to reduce the risk of relapse of mental illness and associated re-offending should the patient be discharged.

\section{Conclusion}

It is not always easy for the RMO to express a clear opinion to the Tribunal as the issues are rarely clearcut and decisions have to be made about degrees of human suffering and risk to others. On the whole, decisions are made on what is absent as far as mental illness is concerned and the probability of what may be present in the future with the problem of relapse of mental illness and associated dangerousness to self or others.

In conclusion, as in all cases of giving evidence, adequate preparation is essential, not just allowing time to prepare reports, but thinking time to anticipate the questions in an oral examination, and plan responses. Time should be allowed for prior discussion in a multi-professional team setting, discussion with the patient, and, where appropriate, family.

It is understandable that the RMO will tend to err on the side of caution in most cases, especially where there has been a history of offending behaviour. When faced with difficult decisions which may affect the safety of others it is often a relief to share the decision with the Tribunal.

Amidst the demands of clinical work it is important not to forget the authority and power of the RMO at the Tribunal and the effects on the individual patient.

Issues of likely co-operation with treatment in the community raise the question of whether the law needs revision to include compulsory treatment or supervision orders.

Since this paper was first written, the Council of the Royal College of Psychiatrists has recommended to the Secretary of State for Health that the Mental Health Act 1983 be amended to incorporate a new order: the "Community Supervision Order". The Council agreed that compulsory treatment is unacceptable but accepted that a small group of patients who are repeatedly admitted to hospital under Detention Orders (S3 or S37), who also require long-term support and supervision, and who are also known to have a history of non-compliance could be made subject to a Community Supervision Order. If subject to such an order the patient could be recalled to hospital if he withdrew co-operation and his mental state deteriorated. The patient could then be encouraged to maintain his independence under supervision in the community rather than be repeatedly admitted.

Introduction of such an amendment to the mental health legislation would have resource implications as it would be untenable unless accompanied by improved community services.

\section{Further reading}

Bluglass, R. (1993) Maintaining the treatment of mentally ill people in the community. British Medical Journal, 306, 159-160.

GaNGLEY, G.E.(1990) The Responsible Medical Officer and Mental Health Review Tribunals. Psychiatric Bulletin, 14, 336-337.

Gostin, L., Rassaby, E. \& Buchanan, A. (1984) Mental Health: Tribunal Procedure. London: Oyez Longman.

Peay, J. (1990) Mental Health Review Tribunals. In Principles and Practice of Forensic Psychiatry (eds. R. Bluglass \& P. Bowden). Edinburgh and London: Churchill Livingstone. Pp 1259-1266.

Royal College of Psychiatrists (1993) Community Supervision Orders. A Report of the Royal College of Psychiatrists.

Woolf, P. G. (1991) The role of the doctor in the Mental Health Review Tribunal. Psychiatric Bulletin, 15, 407-409. 